Research Article

\title{
Probabilistic Assessment of the Safety of Main Cables for Long-Span Suspension Bridges considering Corrosion Effects
}

\author{
Hao Tian $\mathbb{D}^{1,2}$ Jiji Wang $\left(\mathbb{D},{ }^{1}\right.$ Sugong Cao $\mathbb{D D}^{1,3}$ Yuanli Chen, ${ }^{2}$ and Luwei $\mathrm{Li}^{4}$ \\ ${ }^{1}$ Key Laboratory of Road and Bridge Inspection and Maintenance Technology of Zhejiang Province, Hangzhou 311305, China \\ ${ }^{2}$ Zhejiang Institute of Communications, Hangzhou 311112, China \\ ${ }^{3}$ College of Civil Engineering, Tongji University, Shanghai 200092, China \\ ${ }^{4}$ CCCC Highway Consultants Co., Ltd., Beijing 100120, China
}

Correspondence should be addressed to Jiji Wang; wangjiji2009@qq.com

Received 4 November 2020; Revised 22 January 2021; Accepted 4 February 2021; Published 4 March 2021

Academic Editor: Zhongguo John Ma

Copyright (C) 2021 Hao Tian et al. This is an open access article distributed under the Creative Commons Attribution License, which permits unrestricted use, distribution, and reproduction in any medium, provided the original work is properly cited.

\begin{abstract}
This paper presents a reliability analysis to assess the safety of corroded main cables of a long-span suspension bridge. A multiscale probability model was established for the resistance of the main cables considering the length effect and the Daniels effect. Corrosion effects were considered in the wire scale by relating the test results from accelerated corrosion tests to the corrosion stages and in the cable scale by adopting a corrosion stage distribution of the main cable section in NCHRP Report 534. The load effects of temperature, wind load, and traffic load were obtained by solving a finite element model with inputs from in-service monitoring data. The so-obtained reliability index of the main cables reduces significantly after operation for over 50 years and falls below the design target value due to corrosion effects on the mechanical properties of the steel wire. Multiple measures should be taken to delay the corrosion effects and ensure the safety of the main cables in the design service life.
\end{abstract}

\section{Introduction}

The main cable of the suspension bridge is the key loadcarrying and nonreplaceable component, which plays a decisive role in the safety of the suspension bridge in the design service life. Inspections of suspension bridges in Japan have found that high-strength steel (HSS) wires in main cables suffer from corrosion to varying degrees after operation for only several years, which brings uncertainty to the safety of long-span suspension bridges $[1,2]$. The longterm influence of corrosion should be investigated and modelled properly to make guidelines on the maintenance of newly constructed suspension bridges so that the design target of reliability index can be achieved in the whole design service life.

Different methods have been proposed in assessing the safety factors of the main cables of suspension bridges. Matteo et al. [3] estimated the current safety factor of the main cables of the Williamsburg Bridge by adopting two models: the ductile wire model by the use of a Monte Carlo simulation approach and the ductile-brittle wire model by the use of an extreme value distribution approach. Haight et al. [4] proposed to use a type-I extreme value distribution to compute cable safety factors for four suspension bridges. Cremona [5] presented a probabilistic approach for cable residual strength assessment of the Tancarville suspension cables by incorporating the tensile test results, inspection data, and weight-in-motion records. Cheng et al. [6] adopted an artificial neural network-based inverse reliability method to estimate the safety factors of the main cables with a target reliability index. These studies were concerned with the determination of the current safety factors but may not consider the long-term performance of corroded cables under different operation times.

Long-span suspension bridges are generally located in severe corrosive environment which induces corrosion in main cables. The corrosion effects reduce the bearing capacity of the main cables with time and endanger the safety of bridges. Only limited studies have been conducted on the evolution of the reliability index of the main cables under 
corrosion effects. Faber et al. [7] presented a reliability-based method to develop a degradation function in the assessment of parallel wire cables under deterioration by fatigue and corrosion. Elachachi et al. [8] proposed a multiscale model to evaluate the effect of factors (e.g., wire corrosion initiation and corrosion kinetics) on the long-term performance of main cables.

In the present study, a reliability model is developed to assess the long-term performance of corroded main cables in Xihoumen Bridge, a long-span suspension bridge in China. A multiscale probability model is established for the resistance of the main cables considering the length effect and the Daniels effect on steel wires and strands. In addition, corrosion effects are considered in the wire scale by relating the test results from accelerated corrosion tests to the corrosion stages, and in the cable scale by adopting a corrosion stage distribution of the main cable section in NCHRP Report 534 [9]. The load effects of temperature, wind load, and traffic load are obtained by solving an FE model with the in-service monitoring data of temperature, wind, and traffic modes.

\section{Accelerated Corrosion Tests of Cable Wires with Constant Strains}

In companion papers $[10,11]$, an accelerated corrosion test was conducted on high-strength steel (HSS) wires to investigate the effect of strain levels and corrosion time. The HSS wires had a nominal diameter of $5.25 \mathrm{~mm}$ and a strength grade of $1770 \mathrm{MPa}$, which was the same product as those used in the main cables of Xihoumen Bridge, a suspension bridge in China with a $1650 \mathrm{~m}$ central span. Tensile strains in HSS wires were kept at constant levels of 0,1000 , 2000 , and $3000 \mu \varepsilon$ by an especially designed strain-holding device. An upper limit of $3000 \mu \varepsilon$ was adopted as the working strains in the HSS wires of Xihoumen Bridge were between 2000 and $3000 \mu \varepsilon$. The corrosion time was set from 1 to 4 days. A total of 16 sets of test conditions were designed and each set had 3 identical specimens, leading to a total of 48 specimens.

After accelerated corrosion tests, the corrosion state of each specimen was recorded and the cross section of each specimen was measured carefully following GB/T 500822009 [12]. The mechanical behavior of each corroded specimen was then obtained by static tensile tests. A regression analysis of the test results revealed that the yield load and ultimate load exhibited a positive correlation with the cross section. The yield stress and tensile strength were simply related to the minimum diameter of steel wires through regression analysis of test results of the accelerated corrosion tests:

$$
\begin{aligned}
& P_{y}=7.191 d_{\min }+0.855, \\
& P_{u}=8.148 d_{\min }-2.429,
\end{aligned}
$$

where $P_{y}$ and $P_{u}$ are the yield load and ultimate load, respectively, and $d_{\text {min }}$ is the minimum diameter in a corroded steel wire.
In the NCHRP Report 534 [9], four corrosion stages have been defined: Stage 1 refers to wires with spots of zinc oxidation; Stage 2 refers to wires with zinc oxidation on the entire wire surface; Stage 3 refers to wires with spots of brown rust covering up to $30 \%$ of the surface of a $76 \mathrm{~mm}$ to $152 \mathrm{~mm}$ length of wire; and Stage 4 refers to wires with brown rust covering more than $30 \%$ of the surface of a $76 \mathrm{~mm}$ to $152 \mathrm{~mm}$ length of wire. The 48 wire specimens were visually categorized into four corrosion stages according to the NCHRP Report 534 [9]. It was found that the elastic modulus $E$ and the rupture strain $\varepsilon_{u}$ were independent of corrosion stages, while the yield strength $\sigma_{e}$ and tensile strength $\sigma_{u}$ were significantly influenced by the corrosion effects $[10,11]$. The statistical parameters (i.e., average, standard deviation (SD), coefficient of variation $(\mathrm{CoV})$, and distribution model parameters) of the mechanical properties were then determined for the corresponding corrosion stages (Table 1). The average minimum diameter $d_{\min }$ of each corrosion stage was listed in the last column in Table 1.

\section{Resistance of Cables considering Corrosion Effects}

The main cables of Xihoumen Bridge were erected by the Prefabricated Parallel Wire Strand (PPWS) method. Each strand was composed of 127 zinc-coated HSS wires and each cable was composed of 169 strands. The multiscale model, including the scale of wire, the scale of strand, and the scale of cable, proposed by Elachachi et al. [8] was adopted to evaluate the long-term resistance of the main cables considering corrosion effects. The corrosion effects were considered by relating the accelerated corrosion test results in Section 2 to a simplified corrosion map in NCHRP Report 534 [9].

3.1. Wire-Scale Model. The constitutive behavior of a wire governs the mechanical behavior of the main cables. Following Elachachi et al. [8], the constitutive law of each steel wire was modelled by equation (1):

$$
\begin{gathered}
\sigma=\left\{\begin{array}{ll}
E \varepsilon, & \text { if } \sigma<\sigma_{e}, \\
\sigma_{e}+\frac{E\left(\varepsilon-\varepsilon_{e}\right)}{1+C\left(\varepsilon-\varepsilon_{e}\right)}, & \text { if } \sigma>\sigma_{e},
\end{array} \quad \text { with } C=\frac{E \varepsilon_{u}-\sigma_{u}}{\left(\sigma_{u}-\sigma_{e}\right)\left(\varepsilon_{u}-\varepsilon_{e}\right)},\right.
\end{gathered}
$$

where $\varepsilon_{e}$ and $\sigma_{e}$ are the yield strain and stress; $\varepsilon_{u}$ and $\sigma_{u}$ are the ultimate strain and stress; and $E$ is the elastic modulus. All the above parameters were random variables with statistical parameters determined from the tensile test results of specimens after corrosion tests (see Table 1).

A wire is normally modelled as a series system composed of wire segments and the strength of the wire is therefore determined by the weakest segment [5]. The phenomenon of the reduced strength in a long wire compared with small segments is known as the length effect. The tensile strengths 
TABLE 1: Statistical parameters of steel wire distribution functions.

\begin{tabular}{|c|c|c|c|c|c|c|c|}
\hline & Average (MPa) & $\mathrm{SD}(\mathrm{MPa})$ & $\mathrm{CoV}$ & \multicolumn{2}{|c|}{ Distribution model } & \multirow{2}{*}{$\begin{array}{c}\text { Corrosion stage } \\
-\end{array}$} & \multirow{2}{*}{$\begin{array}{c}d_{\min }(\mathrm{mm}) \\
-\end{array}$} \\
\hline E & $2 \times 10^{5}$ & $4 \times 10^{4}$ & 0.2 & Lognormal & $\begin{array}{c}\lambda: 12.2048 \\
\xi: 0.05\end{array}$ & & \\
\hline \multirow{4}{*}{$\sigma_{e}$} & 1712 & 17.12 & 0.01 & Lognormal & $\begin{array}{l}\lambda: 7.445 \\
\xi: 0.0024\end{array}$ & Stage 1 & 5.13 \\
\hline & 1692 & 33.84 & 0.02 & Lognormal & $\begin{array}{l}\lambda: 7.434 \\
\xi: 0.0034\end{array}$ & Stage 2 & 5.07 \\
\hline & 1627 & 48.81 & 0.03 & Lognormal & $\begin{array}{l}\lambda: 7.395 \\
\xi: 0.0043\end{array}$ & Stage 3 & 4.87 \\
\hline & 1526 & 76.29 & 0.05 & Lognormal & $\begin{array}{l}\lambda: 7.330 \\
\xi: 0.0057\end{array}$ & Stage 4 & 4.56 \\
\hline \multirow{4}{*}{$\sigma_{u}$} & 1785 & 17.85 & 0.01 & Lognormal & $\begin{array}{l}\lambda: 7.445 \\
\xi: 0.0024\end{array}$ & Stage 1 & 5.13 \\
\hline & 1763 & 35.26 & 0.02 & Lognormal & $\begin{array}{l}\lambda: 7.434 \\
\xi: 0.0034\end{array}$ & Stage 2 & 5.07 \\
\hline & 1689 & 50.67 & 0.03 & Lognormal & $\begin{array}{l}\lambda: 7.395 \\
\xi: 0.0043\end{array}$ & Stage 3 & 4.87 \\
\hline & 1575 & 78.75 & 0.05 & Lognormal & $\begin{array}{l}\lambda: 7.330 \\
\xi: 0.0057\end{array}$ & Stage 4 & 4.56 \\
\hline$\varepsilon_{u}$ & 0.0189 & 0.0039 & 0.204 & Weibull & $\begin{array}{c}m_{\varepsilon}: 4.15 \\
\varepsilon_{\min }: 0.016 \\
\varepsilon_{0}: 0.014\end{array}$ & - & - \\
\hline
\end{tabular}

of the wire segments can be considered as random variables $Z$ with identical distribution functions. The Weibull distribution with parameters $\lambda, u$, and $k$ was adopted to model the distribution function $F_{z}(z)$ [7]:

$$
F_{Z}(z)=1-e^{-\lambda(z / u)^{k}}
$$

The mean value and standard deviation of $Z$ are given by

$$
\begin{aligned}
& E(z)=u \lambda^{(-1 / k)} \Gamma\left(1+\frac{1}{k}\right), \\
& D(z)=u^{2} \lambda^{(-2 / k)}\left[\Gamma\left(1+\frac{2}{k}\right)-\Gamma^{2}\left(1+\frac{1}{k}\right)\right],
\end{aligned}
$$

where the scale factor $\lambda$ is defined as the ratio of the clamp length $L$ and the relative length $L_{\rho}$. For the Xihoumen Bridge, the clamp length was $18 \mathrm{~m}$ and the length of coupons for tensile tests was $0.3 \mathrm{~m}$. Therefore, the coefficient $\lambda$ was 60 . By applying the maximum likelihood method on observations of tensile strength from coupon tests, another two parameters $u$ and $k$ for the Weibull distribution were found to be 1770 and 72.62, respectively. Figure 1 shows examples of the stress-strain curves of steel wires in Corrosion Stage 1 considering the length effect.

3.2. Strand-Scale Model considering Daniels Effect. The strand of a cable was made of a bundle of parallel wires. The strength of a parallel system with $n$ components can be described by the normal distribution with mean value and standard deviation as follows $[13,14]$ :

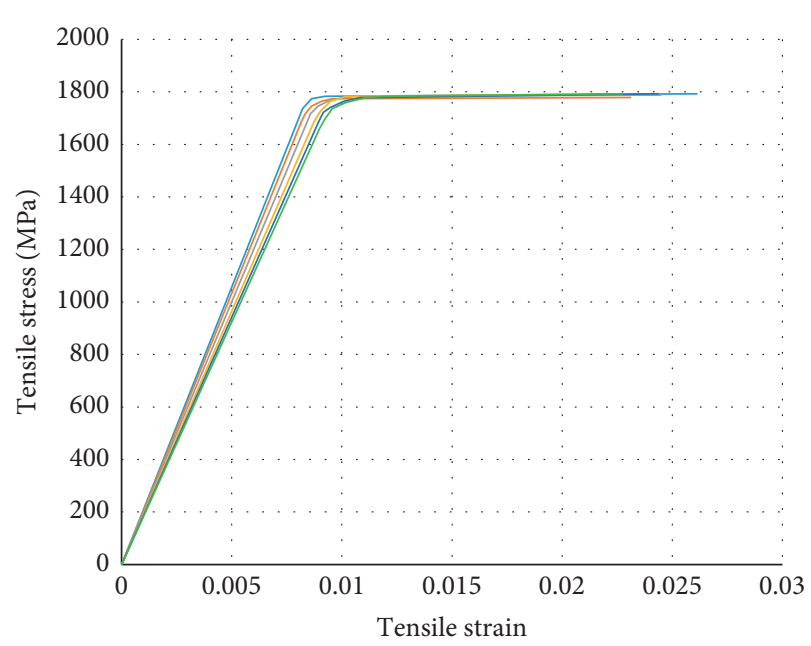

FIGURE 1: Examples of stress-strain curves of wires in Corrosion Stage 1 .

$$
\begin{aligned}
& E_{n}=n x_{0}\left(1-F_{Z}\left(x_{0}\right)\right)+c_{n}, \\
& D_{n}=x_{0}\left[n F_{Z}\left(x_{0}\right)\left(1-F_{Z}\left(x_{0}\right)\right)\right]^{(1 / 2),}
\end{aligned}
$$

where $c_{n}$ is a correction term and may be determined from

$$
c_{n}=0.966 n^{(1 / 3)} a,
$$

where, $a^{3}=\frac{f_{z}^{2}\left(x_{0}\right) x_{0}^{4}}{\left(2 f_{z}\left(x_{0}\right)+x_{0} f_{z}^{\prime}\left(x_{0}\right)\right)}$. 
$f_{Z}\left(x_{0}\right)$ is the density function for the wire strength and $x_{0}$ is the solution of the following equation:

$$
x_{0}=\max \left\{x\left(1-F_{Z}(x)\right)\right\} .
$$

In particular, if $Z$ is Weibull-distributed $F_{Z}(x)=1-e^{-\lambda(x / u)^{k}}, x_{0}$ can be determined from

$$
x_{0}=\left[\frac{1}{\lambda k}\right]^{(1 / k)} u,
$$

where $u$ is the expectation of the tensile strength of wires and was conservatively taken as $1525.8 \mathrm{MPa} ; \lambda$ is the size scale factor and was taken as 60; and $k$ is a factor obtained from tensile test results and was found to be 72.62. $x_{0}$ is therefore 1359.5 using equation (7). The strength reduction factor is 0.9255 for the averaged strength of wires in a strand with respect to that of a single wire. Figure 2 shows the averaged stress-strain curves of steel wires in strands with different corrosion levels considering the length effect and Daniels effect.

3.3. Cable-Scale Model. In NCHRP Report 534 [9], the corrosion stages of all steel wires in the main cable of one suspension bridge were recorded in a thorough internal inspection conducted when the bridge was 30 years old. The cross section was divided into eight sectors and a number of rings. In the present study, the distribution of corrosion stages of steel wires in a cross section was assumed to be symmetric about the vertical line during the whole service life and similar to the distribution in NCHRP Report 534 [9] when Xihoumen Bridge operates after 30 years. Six rings in the radial direction were used to further divide each sector (see Figure 3). The corrosion stages of rings in each sector were summarized in Table 2. It should be noted that Corrosion Stage 3.5 means that half of the wires were in Corrosion Stage 3 and the other half were in Corrosion Stage 4.

The original diameter $d_{0}$ of the steel wire was $5.25 \mathrm{~mm}$. The minimum diameters at Corrosion Stages 1 to 4 were $5.13 \mathrm{~mm}, 5.07 \mathrm{~mm}, 4.87 \mathrm{~mm}$, and $4.56 \mathrm{~mm}$, respectively, determined by equation (1) or equation (2) with the yield stress or ultimate stress already known (see Table 1). The diameter at any age can be obtained once the diameter loss rate is known, and the yield load and ultimate load of a steel wire at any location and any age can then be determined by equations (1) (2). Long-term corrosion tests on mild steel have revealed that the corrosion rate falls considerably during the first 6 years of exposure and subsequently levels out [15]. In the present paper, the diameter loss was therefore assumed to be in a nonlinear relationship with corrosion time:

$$
\Delta d=d_{\min , 0}-d_{\min , t}=a \sqrt{t},
$$

where $t$ is corrosion time (year); $a$ is diameter loss rate and equal to $0.022,0.033,0.069$, and 0.126 for steel wires in Corrosion Stages 1 to 4 after 30-year operation based on the minimum diameters at Corrosion Stages 1 to 4 .

The Monte Carlo method was used to generate 20 million random variables to represent the mechanical properties of steel wires. The probability of steel wires falls in
Sectors 1 to 6 was $2.78 \%, 8.33 \%, 13.89 \%, 19.44 \%, 25.00 \%$, and $30.56 \%$, respectively, according to the area of sectors. By incorporating the wire scale, strand-scale, and cable-scale models discussed in the previous sections, a probability model for the resistance of the main cables in service after operation for different years can be obtained (see Figure 4).

\section{Load Effects on the Main Cables of Xihoumen Bridge Using In-Service Data}

A monitoring system has been built on Xihoumen Bridge to ensure the safety of the long-span bridge, with temperature, wind velocity, and traffic load continuously recorded. In this section, the load effects on the main cables of Xihoumen Bridge induced by dead load, temperature, wind, and traffic were obtained by solving a three-dimensional finite element (FE) model incorporating in-service data. The main cables in the FE model were divided into 10 sectors and the responses were averaged in each sector (see Figure 5). The dead load effects of each sector are shown in Table 3.

4.1. Force Effects due to Temperature. The frequency distribution function of temperature in a year was obtained by a nonlinear regression analysis of the recorded temperature data (see Figure 6):

$$
f(x)=a_{1} e^{\left[-\left(x-b_{1}\right) / c_{1}\right]^{2}}+a_{2} e^{\left[-\left(x-b_{2}\right) / c_{2}\right]^{2}},
$$

where $a_{1}=1.44 \times 10^{4}, b_{1}=17.13, c_{1}=7.55, a_{2}=-1.44 \times$ $10^{4}, b_{2}=17.13, c_{2}=7.54$. Therefore, the probability density of the force effects due to uniform temperature can be obtained from the simulation results of the FE model under different temperatures. Figure 7 shows the probability density of stresses in cable sector 9 , of which the tensile stress was the largest among all sectors.

4.2. Wind Load Effects. Similar to the temperature effect, the frequency distribution function of wind velocity in a year was firstly obtained by a nonlinear regression analysis of the recorded data (see Figure 8):

$$
f(x)=a_{1} e^{\left[-\left(x-b_{1}\right) / c_{1}\right]^{2}},
$$

where $a_{1}=44.41, b_{1}=6.35, c_{1}=4.60$. By importing different wind velocity in the FE model, the tensile stress from wind load effects can be obtained at different wind velocities and the probability density curve of cable sector 9 is shown in Figure 9 as an example. The wind load effect was the largest in cable sector 9, with extreme tensile stress of $586.08 \mathrm{MPa}$.

4.3. Traffic Load Effects. The vehicle load involves complicated combinations of the weight, quantity, and position of vehicles. To simplify the analysis, 100 real traffic load modes were extracted from the Weigh in Motion (WIM) system of Xihoumen Bridge and were input in the FE model to obtain the response of each sector (see Figure 10). Tensile stress 


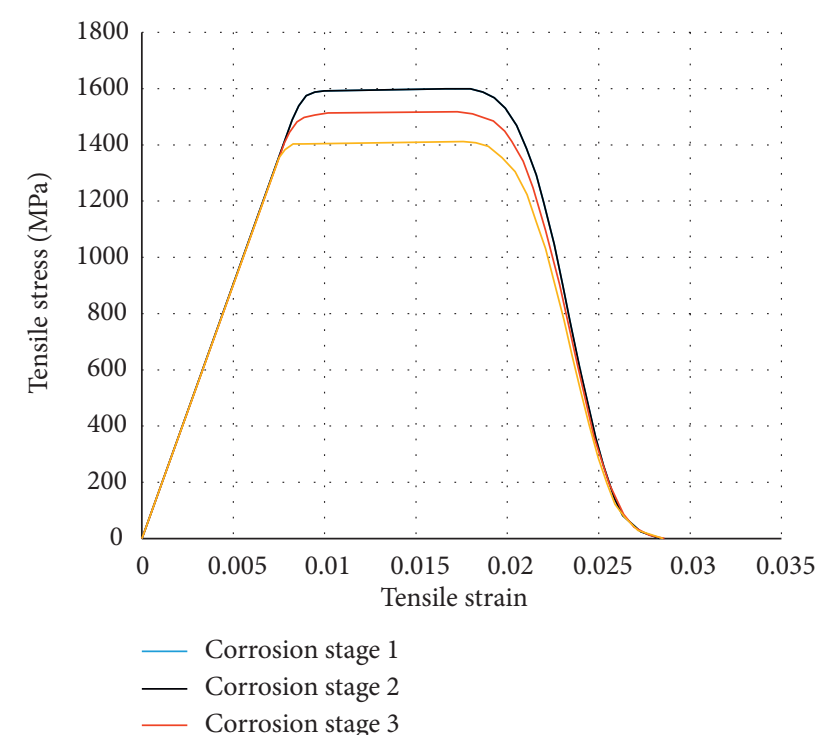

Figure 2: The averaged stress-strain curves of steel wires in different corrosion stages considering the length effect and Daniels effect.

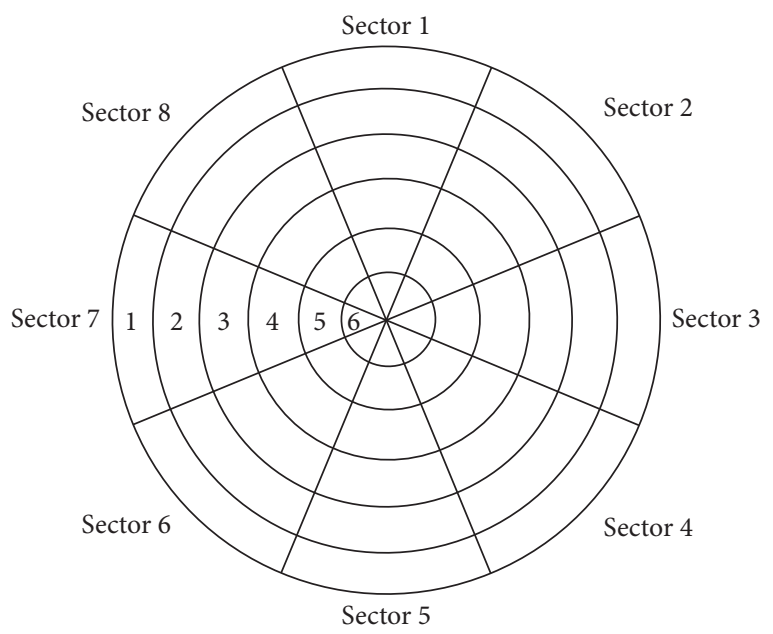

Figure 3: Division of the typical cross section.

TABLe 2: Corrosion stages in the critical cross section.

\begin{tabular}{lcccccc}
\hline & Ring 1 & Ring 2 & Ring 3 & Ring 4 & Ring 5 & Ring 6 \\
\hline Sector 1 & 3.5 & 3 & 3 & 2 & 2 & 2 \\
Sector 2 & 4 & 3 & 3 & 2 & 2 & 2 \\
Sector 3 & 4 & 3 & 3 & 3 & 2 & 2 \\
Sector 4 & 4 & 3 & 3 & 3 & 2 & 2 \\
Sector 5 & 4 & 3.5 & 3 & 3 & 3 & 3 \\
\hline
\end{tabular}

Note: Ring 1 was the ring near the surface; corrosion stages in Sectors 6, 7, and 8 were the same as Sectors 4,3 , and 2, respectively.

limits for each cable sector were determined based on $95 \%$ level of confidence, which means only $5 \%$ of the traffic load modes will induce larger tensile stress in each cable sector. Table 4 summarizes the traffic load effects of each cable sector.

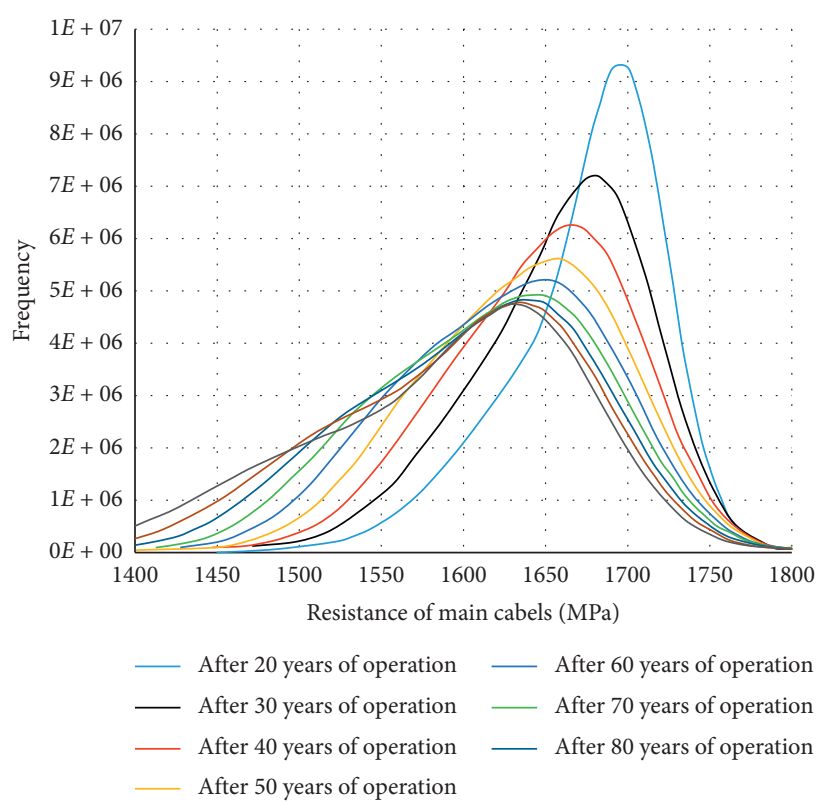

FIgure 4: Probability model for the resistance of the main cables.

4.4. Combination of Load Effects. Normally, there are traffic controls in Xihoumen Bridge in extreme weather such as typhoons. Therefore, the combination of wind load and traffic load was not considered. For the live loads, the force effect due to temperature was combined with wind load effects or traffic loads. Load combination coefficients and safety factors were not considered in the present study. Two load combinations shown in Table 5 were adopted for each main cable sector.

\section{Probabilistic Assessment of the Safety of Corroded Main Cables}

In reliability analysis, the concept of limit state is generally used to define a failure. In assessing the reliability of the main cables, an ultimate limit state function was defined in the following equation:

$$
Z(R, S)=R-S=0,
$$

where $R$ is the resistance of the main cables and $S$ is the load effects as discussed in Sections 3 and 4, respectively. Both the resistance and load effects are functions of multiple parameters subjected to statistical variation. Once the distribution of the resistance and load effects are determined, the probability of failure can be computed by

$$
P_{f}=P(Z<0) .
$$

The probability of failure can be related to the reliability index $\beta$ in the following equation:

$$
P_{f}=\Phi(-\beta) \text {. }
$$

5.1. Extrapolation of the Resistance by Rice Model. The resistance $R$ in the low stress state is of main concern in the 


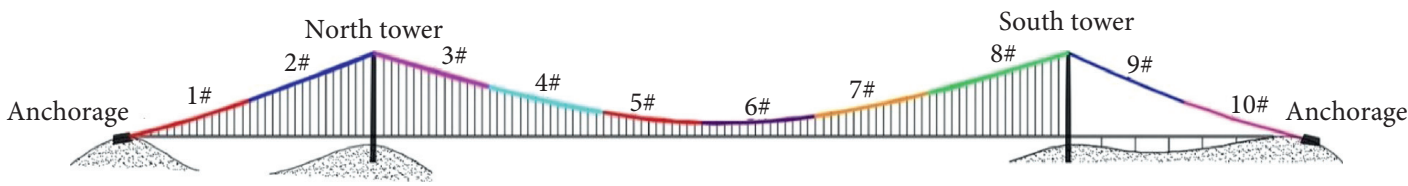

Figure 5: Main cable sectors of the Xihoumen Bridge.

Table 3: Dead load effects.

\begin{tabular}{|c|c|c|c|c|c|c|c|c|c|c|}
\hline Sector number & 1 & 2 & 3 & 4 & 5 & 6 & 7 & 8 & 9 & 10 \\
\hline Stress $(\mathrm{MPa})$ & 550.31 & 575.42 & 568.31 & 551.80 & 550.49 & 549.46 & 556.37 & 576.28 & 587.39 & 578.76 \\
\hline
\end{tabular}

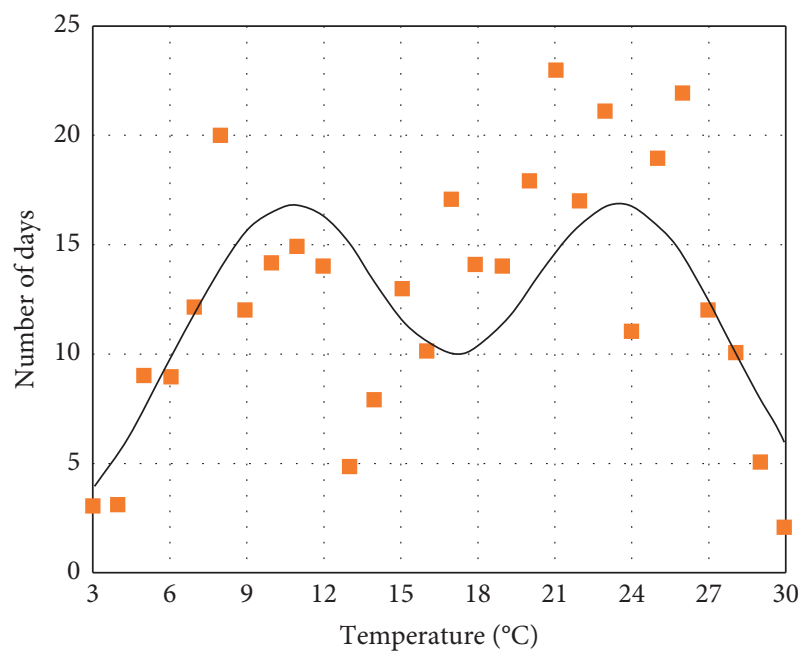

FIGURE 6: The frequency distribution of temperature in the period of one year.

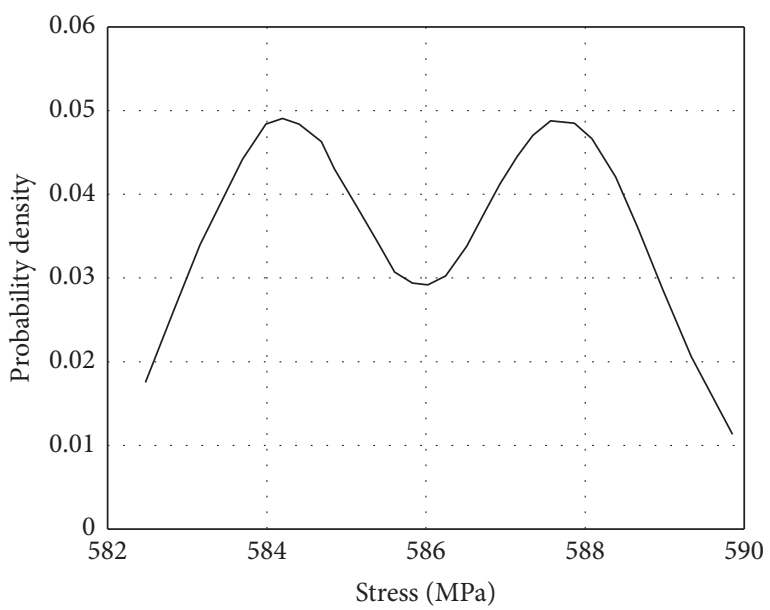

FIGURE 7: The probability density of tensile stress in cable sector 9 due to temperature effects.

present study to obtain the probability of failure. It has been mentioned previously that the working strains in the HSS wires of Xihoumen Bridge were between 2000 and $3000 \mu \varepsilon$ (corresponding to $400 \sim 600 \mathrm{MPa}$ ). Therefore, the probability density of the resistance smaller than $600 \mathrm{MPa}$ is essential to capture failure cases. Figure 11 shows the logarithmic

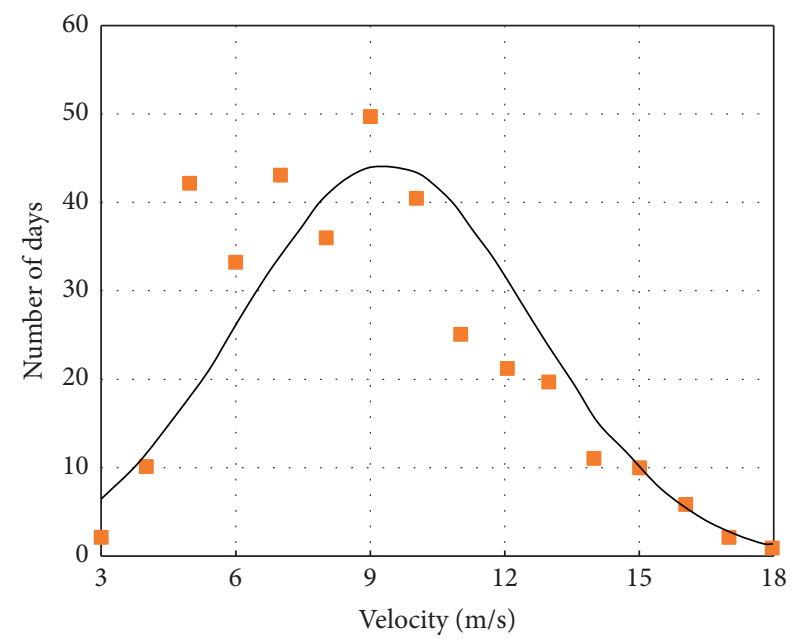

FIgURE 8: The frequency distribution of wind velocity.

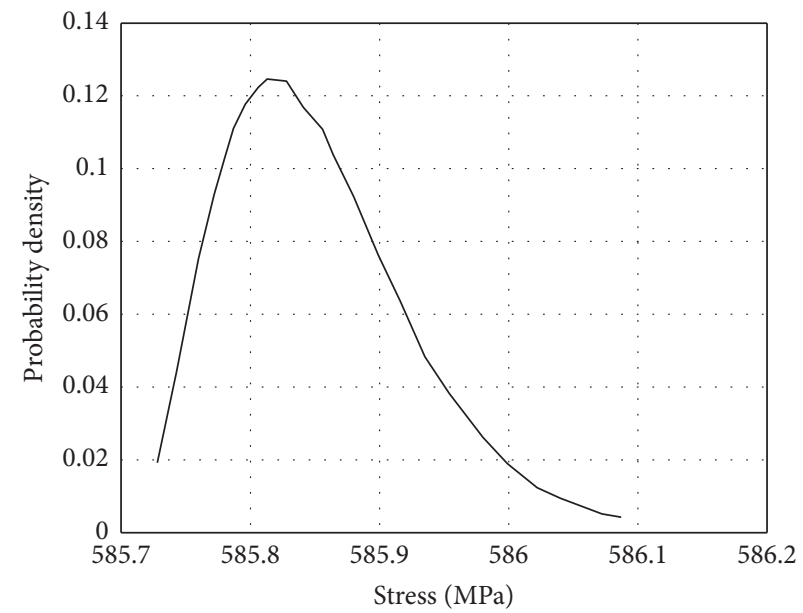

FIgURE 9: The probability density curve of tensile stress in cable sector 9 due to wind load effects.

frequency of the resistance of the main cables after a 40-year operation as an example. It can be seen in Figure 11 that the frequency of resistance smaller than $784.56 \mathrm{MPa}$ is zero. The resistance of the main cables in the low stress part should be extrapolated properly. 


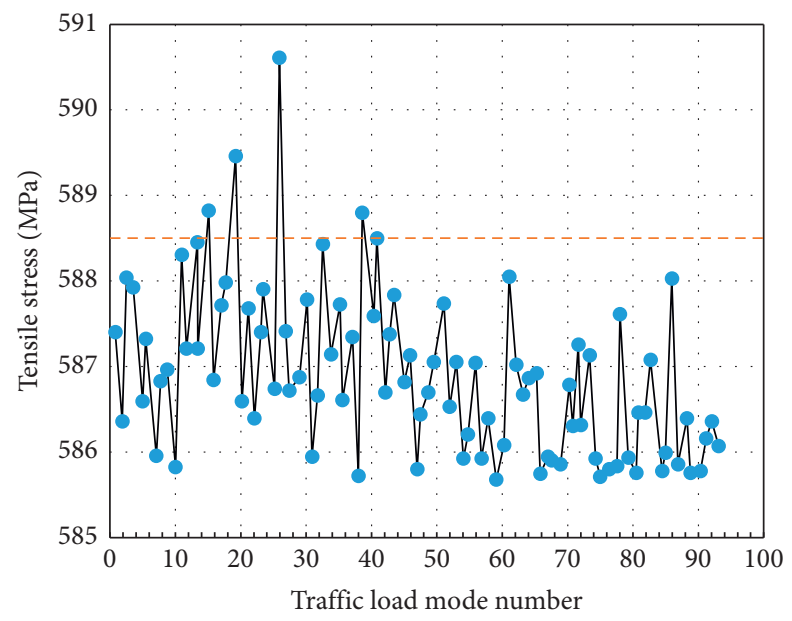

Figure 10: Tensile stress in sector 9 under 100 traffic load modes.

TABle 4: Traffic load effects.

\begin{tabular}{lcccccccccc}
\hline Sector number & 1 & 2 & 3 & 4 & 5 & 6 & 7 & 8 & 9 & 10 \\
\hline Stress $(\mathrm{MPa})$ & 551.5 & 576.7 & 569.1 & 552.6 & 551.3 & 552.1 & 577.2 & 577.3 & 588.5 & 579.8 \\
\hline
\end{tabular}

TABLE 5: Combination of load effects.

\begin{tabular}{lcc}
\hline Load combination & Permanent load & Live load \\
\hline 1 & Dead load & Load effect due to temperature + wind load \\
2 & Dead load & Load effect due to temperature + traffic load \\
\hline
\end{tabular}

The Rice formula was proposed by Rice [16] to analyze the random noise and was used in the extrapolation of load effects of bridge structures by Cremona [5, 17]. The Rice formula requires the load process to be stationary and Gaussian. The validity of the Gaussian hypothesis in the load process of the bridge has been verified by tests [18] and is particularly the case for large bridges. It follows that the mean outcrossing rate $v(x)$ for a level $x>0$ is expressed by the Rice formula:

$$
v(x)=\left(\frac{1}{2 \pi}\right)\left(\frac{\dot{\sigma}}{\sigma}\right) \exp \left(-\frac{(x-m)^{2}}{2 \sigma^{2}}\right),
$$

where $\sigma, \dot{\sigma}$, and $m$ are the standard deviation of load process $X$, the standard deviation of the stochastic process derivative $\dot{X}$, and the process mean. Take the logarithm on both sides of equation (14) and organize it as follows:

$$
y=\ln (v(x))=a_{0}+a_{1} x+a_{2} x^{2},
$$

where $a_{0}=\ln \left(v_{0}\right)-\left(m^{2} / 2 \sigma^{2}\right), a_{1}=\left(m / \sigma^{2}\right), a_{2}=-\left(1 / 2 \sigma^{2}\right)$.

The use of Rice formula to extrapolate the extreme value of resistance is basically fitting the tail of the outcrossing histogram of resistance. The outcrossing rate histogram can be obtained by dividing the number of outcrossing by the system recording time (days). Intervals of the so-obtained histogram are close to $v(x)$. The working strains in the HSS wires of Xihoumen Bridge were between 400 and $600 \mathrm{MPa}$. Therefore, the resistance of the main cables smaller than
$600 \mathrm{MPa}$ is the main concern in the regression analysis of equation (17). Take the logarithmic frequency of the resistance of the main cables after a 40-year operation as an example (see Figure 11). The resistance between $784.56 \mathrm{MPa}$ and $1587 \mathrm{MPa}$ was used to fit equation (17) to predict the frequency of the resistance smaller than $784.56 \mathrm{MPa}$. The probability density of the resistance smaller than $600 \mathrm{MPa}$ was therefore obtained and shown in Figure 12.

5.2. Reliability Index and Failure Probability. In the previous sections, the probability density function of resistance $R$ was established by using a three-scale model and was extrapolated in the low stress part by the Rice model. The corrosion effects on the mechanical behavior of wires were considered by categorizing four corrosion stages and were incorporated into the cable-scale model under the assumption that the corrosion stage distribution of wires after a 30-year operation was the same as that of an example in NCHRP Report 534 [9]. The load effects of the dead load, temperature, wind load, and traffic load were obtained by solving the FE model of Xihoumen Bridge incorporating in-service monitoring data. The failure probability of the main cables under different operating years was then calculated by numerical integration of the probability density function for the part of $Z=\mathrm{R}-\mathrm{S}<0$. Figure 13 shows the flowchart of the reliability analysis procedures. The reliability index of the main cable structure was then obtained through equation (16). 


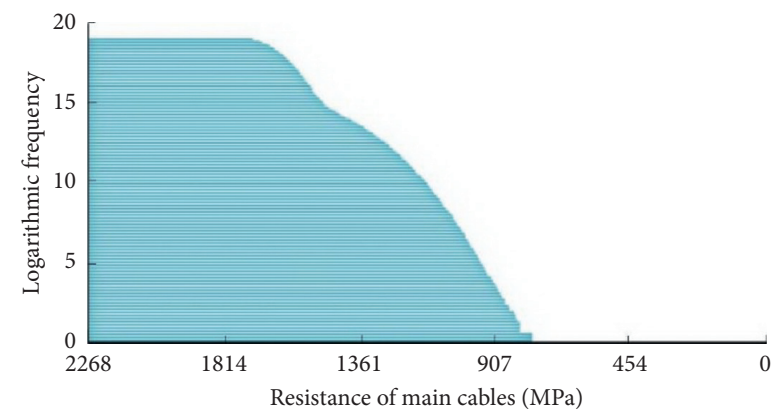

FIGURE 11: Logarithmic frequency of resistance after a 40-year operation.

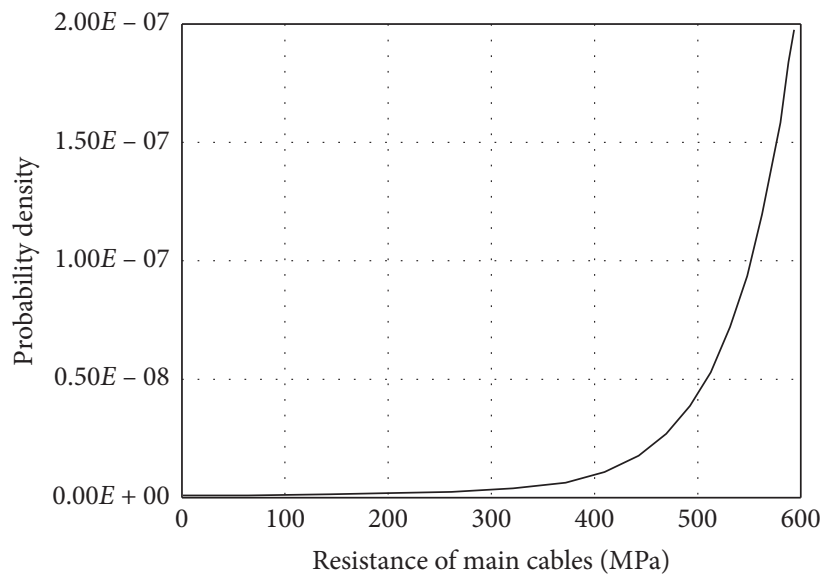

Figure 12: The probability density of resistance of the main cable predicted from the Rice formula.

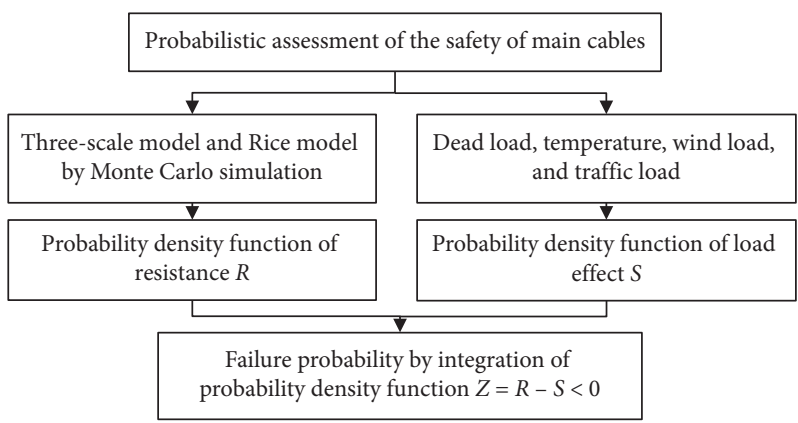

FIGURE 13: Flowchart of the assessment of the safety of main cables.

The main cables of the suspension bridge are loadcarrying and nonreplaceable components. The safety of the main cables is of great importance and the safety factor should be maintained above a large target value, such as 5.2 for safety class I bridges (brittle failure) in Chinese design code [19]. Table 6 and Figure 14 show the reliability index and failure probability after different operation years. It can be seen in Figure 14 that the reliability index reduces significantly after operation for 50 years due to corrosion effects on the mechanical properties of the steel wire. The reliable index falls below the required target value of 5.2 after operation for only 50 years, which brings uncertainty to the safety of the long suspension bridge in the design service life of over 100 years. The analysis result implies the importance of maintenance conducted on the main cables before corrosion on HSS wires takes place. Apart from applying 
TABLE 6: Reliability index and failure probability with different operation times.

\begin{tabular}{lccccc}
\hline Operation time (year) & 20 & 30 & 40 & 50 & 60 \\
\hline Reliability index & 11.17 & 9.39 & 7.04 & 5.39 & 4.11 \\
Failure probability & $2.73 \times 10^{-29}$ & $3.09 \times 10^{-21}$ & $9.27 \times 10^{-13}$ & $3.5 \times 10^{-8}$ & $1.95 \times 10^{-5}$ \\
Operation time (year) & 70 & 80 & 90 & 2.84 & 100 \\
Reliability index & 3.44 & 3.06 & $1.12 \times 10^{-3}$ & $2.29 \times 10^{-3}$ & $3.65 \times 10^{-3}$ \\
Failure probability & $2.86 \times 10^{-4}$ & & - \\
\hline
\end{tabular}

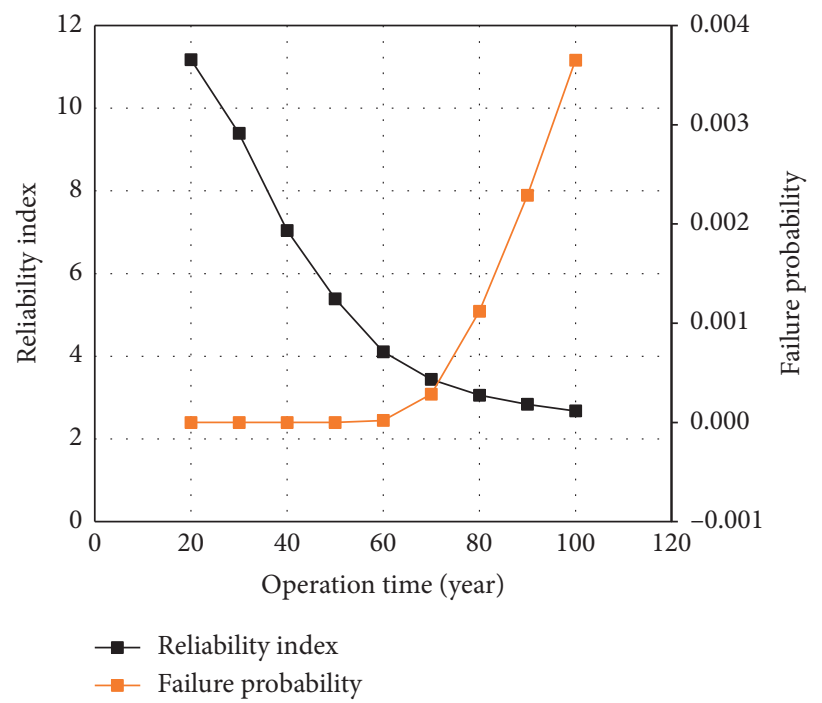

FIGURE 14: Reliability index and failure probability.

coating materials on the main cables, supplementary measures should also be taken, such as the use of a dehumidification system to reduce humidity in the main cables.

\section{Conclusion}

The main cables of suspension bridges are the key loadcarrying and nonreplaceable components. Inspections of suspension bridges around the world have found that steel wires in the main cables suffer from corrosion to varying degrees, which brings uncertainty to the safety of long-span suspension bridges. This paper conducted a reliability analysis to predict the evolution of the reliability index of corroded main cables of a long-span suspension bridge. In detail, the following work has been done:

(1) A multiscale probability model was established for the resistance of the main cables considering the length effect and the Daniels effect on steel wires and strands. In addition, corrosion effects were considered in the wire scale by relating the test results from accelerated corrosion tests to the corrosion stages, and the corrosion stage distribution of the main cable section in the NCHRP report was used to define the corrosion stages in the cable-scale model.

(2) The load effects of temperature, wind load, and traffic load were obtained by solving the FE model with inputs from in-service monitoring data. The two most unfavorable load combinations were considered.

(3) The resistance probability model of the main cable was extrapolated in the low stress part using the Rice formula, and a nonlinear corrosion evolution model was adopted to consider the reduction in mechanical properties of corroded steel wires.

(4) The failure probability and reliability index of the main cables at different operation years was obtained and the results show that the reliability reduces significantly after operation for 50 years due to corrosion effects on the mechanical properties of the steel wire.

In the present study, the corrosion effects on the longterm mechanical behavior of main cables have been successfully considered. The simulation result indicates that the reliability index of the main cables will fall much lower than the design target value if no preventative measures are undertaken on the main cables before corrosion begins. Apart from the traditional way of applying coating materials on the main cables, supplementary measures should also be taken, such as the use of a dehumidification system to reduce humidity in the main cables. It should be noted that the performance change of the main cables due to corrosion was assumed to have no influence on the load effects and the stress states. Besides, the cracks of the steel wire were not considered in the present study, while crack may induce 
brittle rupture of HSS wires and reduce the resistance of the main cables. Future research should be carried out with the effect of cracks taken into consideration.

\section{Data Availability}

Previously reported experimental data were used to support this study and are available at DOI:10.3390/ma12050753. These prior studies (and datasets) are cited at relevant places within the text as reference [11].

\section{Conflicts of Interest}

The authors declare no conflicts of interest.

\section{Authors' Contributions}

H. Tian initiated and supervised the research; J. Wang wrote the paper and analyzed the results; S. Cao conducted finite element analysis; R. Ma offered advice and supervision; and L. Li collected and analyzed the monitoring data.

\section{Acknowledgments}

This research was supported by Zhejiang Provincial Natural Science Foundation of China under Grant no. LGF18E08002 and the National Natural Science Foundation of China under Grant no. 51878493. The authors are also grateful for the financial support from the Project of Science and Technology Program of Department of Transport, Zhejiang Province (2014H20, 2019052, and 2020048).

\section{References}

[1] S. Shoichi and F. Kazuhiko, "Corrosion protection of suspension bridge cables," Construction of Civil Engineering Structures, vol. 38, no. 7, pp. 35-37, 1997.

[2] A. Chen, D. M. Frangopol, and X. Ruan, Bridge Maintenance, Safety, Management and Life Extension, CRC Press, Boca Raton, FL, USA, 2014

[3] J. Matteo, G. Deodatis, and D. P. Billington, "Safety analysis of suspension-bridge cables: Williamsburg bridge," Journal of Structural Engineering, vol. 120, no. 11, pp. 3197-3211, 1994.

[4] R. Q. Haight, D. P. Billington, and D. Khazem, "Cable safety factors for four suspension bridge," Journal of Bridge Engineering, vol. 2, no. 4, pp. 157-167, 1997.

[5] C. Cremona, "Probabilistic approach for cable residual strength assessment," Engineering Structures, vol. 25, no. 3, pp. 377-384, 2003.

[6] J. Cheng, C. S. Cai, and R.-C. Xiao, "Estimation of cable safety factors of suspension bridges using artificial neural networkbased inverse reliability method," International Journal for Numerical Methods in Engineering, vol. 70, no. 9, pp. 11121133, 2007.

[7] M. H. Faber, S. Engelund, and R. Rackwitz, "Aspects of parallel wire cable reliability," Structural Safety, vol. 25, no. 2, pp. 201-225, 2003.

[8] S. M. Elachachi, D. Breysse, S. Yotte, and C. Cremona, "A probabilistic multi-scale time dependent model for corroded structural suspension cables," Probabilistic Engineering $\mathrm{Me}$ chanics, vol. 21, no. 3, pp. 235-245, 2006.
[9] R. M. Mayrbaurl and S. Camo, Guidelines for Inspection and Strength Evaluation of Suspension Bridge Parallel-Wire Cables, p. 534, Transportation Research Board, Washington, DC, USA, 2004.

[10] F. Xu, Y. Chen, X. Zheng, R. Ma, and H. Tian, "Experimental study on corrosion and mechanical behavior of main cable wires considering the effect of strain," Materials, vol. 12, no. 5, p. 753, 2019.

[11] A. Chen, Y. Yang, R. Ma, L. Li, H. Tian, and Z. Pan, "Experimental study of corrosion effects on high-strength steel wires considering strain influence," Construction and Building Materials, vol. 240, p. 117910, 2020.

[12] GB/T 50082, Standard for Test Methods of Long-Term Performance and Durability of Ordinary Concrete, China Architecture Publishing, Beijing, China, 2009.

[13] H. E. Daniels, "The statistical theory of the strength of bundles of threads," Proceedings of the Royal Society of London. Series A. Mathematical and Physical Sciences, vol. 183, pp. 405-435, 1945.

[14] S. Gollwitzer and R. Rackwitz, "On the reliability of Daniels systems," Structural Safety, vol. 7, no. 2-4, pp. 229-243, 1990.

[15] D. De la Fuente, I. Díaz, J. Simancas, B. Chico, and M. Morcillo, "Long-term atmospheric corrosion of mild steel," Corrosion Science, vol. 53, no. 2, pp. 604-617, 2011.

[16] S. O. Rice, "Mathematical analysis of random noise," in Selected Papers in Noise and Stochastic Processes, N. Wax, Ed., Dover Publications, Mineola, NY, USA, 1954.

[17] C. Cremona, "Optimal extrapolation of traffic load effects," Structural Safety, vol. 23, no. 1, pp. 31-46, 2001.

[18] O. Ditlevsen, "Traffic loads on large bridges modeled as whitenoise fields," Journal of Engineering Mechanics, vol. 120, no. 4, pp. 681-694, 1994.

[19] JTG 2120, Unified Standard for Reliability Design of Highway Engineering Structures, China Communications Press, Beijing, China, 2020. 